
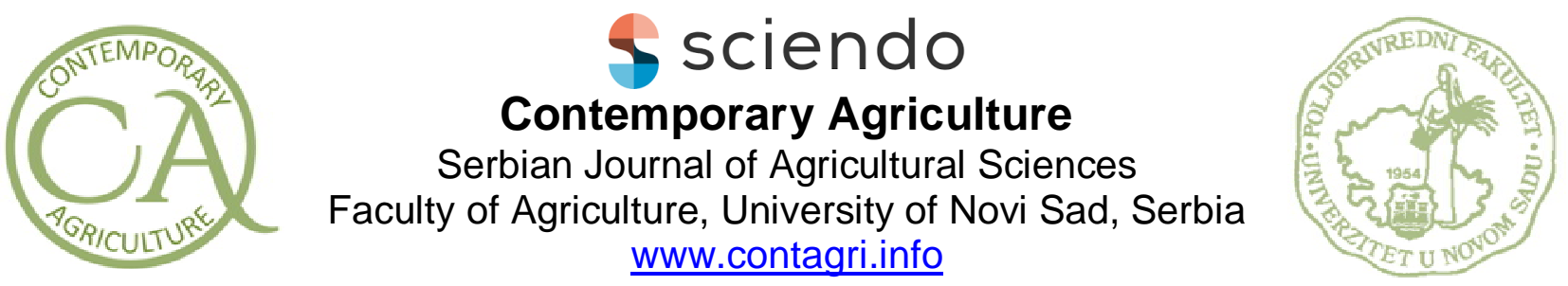

Original scientific paper

UDC: $599.735 .5 .: 665.7 .038$

DOI: 10.2478/contagri-2019-0015

\title{
ANTIOXIDANT EFFECTS OF MARIGOLD (CALENDULA OFFICINALIS) FLOWER EXTRACT ON THE OXIDATIVE BALANCE OF BOVINE SPERMATOZOA
}

\author{
FILIP BENKO, VALENTÍNA PALKOVIČOVÁ, MICHAL ĎURAČKA, JÚLIUS ÁRVAY, \\ NORBERT LUKÁC E EVA TVRDÁ* \\ Faculty of Biotechnology and Food Sciences, Slovak Agricultural University, Tr. A. Hlinku 2, 94976 Nitra, \\ Slovakia \\ *Corresponding author: evina.tvrda@gmail.com
}

\begin{abstract}
SUMMARY
The aim of our study was evaluation of potential antioxidant effects of marigold (Calendula officinalis) extract and assessment of its in vitro impact on the selected quality parameters of bovine spermatozoa. Marigold is medicinal herb from the family Asteraceae native to southern Europe, and it commonly used in pharmacology and medicine. Its well-known positive properties include antioxidant, antibacterial, antiflammatory, antiviral, antifungal, antihelmintic and wound-healing activities. In this study, the flower extracts were subjected to high performance liquid chromatography (HPLC), which identified especially phenolic acids (rosmarinic and chlorogenic acids) and polyphenols (rutin, kaempferol, resveratrol, quercetin and apigenin). These substances are known for their antioxidant activity and protective effects against oxidative stress. For our experiments, 10 samples of semen from sexually mature Holstein bulls were collected on a single day by using an artificial vagina, diluted in physiological saline solution and exposed to solutions with different concentration of marigold flower extract $(75,150$ and 300 $\mu \mathrm{g} / \mathrm{mL}$ ). Selected quality parameters (motility, mitochondrial activity, production of reactive oxygen species - ROS, protein oxidation and lipid peroxidation - LPO) were analyzed after 0,2 and 24 hours of in vitro culture. The motility evaluation was performed by using the computer-assisted sperm analysis (CASA) method. This method revealed that 75 and $150 \mu \mathrm{g} / \mathrm{mL}$ extract had positive effects and increased the motility $(P<0.01)$ and mitochondrial activity $(P<0.0001)$ of bovine spermatozoa compared to the control group following 2 and 24 hours. This phenomenon was observed also in case of ROS production, protein oxidation and LPO. Marigold extract concentrations of 75 and $150 \mu \mathrm{g} / \mathrm{mL}$ decreased the levels of ROS, protein oxidation and damage to the membranes caused by LPO compared to the control group $(P<0.05 ; P<0.01)$ at time 2 and 24 hours. At the same time, 300 $\mu \mathrm{g} / \mathrm{mL}$ extract exhibited positive, although less significant, effects compared to 75 and $150 \mu \mathrm{g} / \mathrm{mL}$ extracts. The data acquired from our study confirm that 75 and $150 \mu \mathrm{g} / \mathrm{mL}$ of marigold flower extract have positive effects on the motility and mitochondrial activity of bovine spermatozoa, and decrease ROS generation, LPO and protein oxidation in spermatozoa. Based on our results, the flower extract from marigold could be used for protection against oxidative stress in in vitro cultures of male gametes.
\end{abstract}

Key words: marigold, bull, motility, male gametes, antioxidant activity

Abbreviations: BSA - bovine serum albumin; DMSO - dimethyl sulfoxide; DNA - deoxyribonucleic acid; DNPH - 2,4-dinitrophenylhydrazine; EPR - electron paramagnetic resonance; HPLC - high performance liquid chromatography; MDA - malondialdehyde; MTT - mitochondrial toxicity test; OS - oxidative stress; PMNs polymorphonuclear leukocytes; PS - saline solution; PT - pentacyclic triterpenes; RNS - reactive nitrogen species; ROS - reactive oxygen species; TBARS - thiobarbituric acid reactive substances 


\section{INTRODUCTION}

Nowadays, oxidative stress (OS) is responsible for defective sperm function and male sub- or infertility. Sperm cells are highly vulnerable to OS because of their limited levels of antioxidant defenses as well as damage detection and repair mechanisms. Furthermore, spermatozoa have large amounts of unsaturated fatty acids in their cell membranes and cytoplasm. Seminal OS is characterized by redox imbalance along with increased reactive oxygen species (ROS) production, decreased antioxidant capacity and reduced sperm motility. The imbalance between the production of ROS and the capacity of available antioxidants leads to a redox paradox and ROS-inflicted damage to the cells (Bisht et al., 2017; Alahmar, 2019). Among the complications associated with OS, poor fertilization rates and embryogenesis, pregnancy loss and birth defects are among the most prominent (Elmussareh et al., 2015).

Numerous studies examine the ability of medical plants to reduce the negative effects of OS. Marigold, also known as Calendula officinalis, is used in the western and Asian countries for its anti-inflammatory properties. Extracts from this herb exhibit various pharmacological activities which include antioxidant, antibacterial, antifungal, antiinflammatory, antiviral, antihelmintic and wound-healing activities. This plant also possesses cytotoxic effects on tumor cells and anticancer activity. The main components responsible for the biological activity of $C$. officinalis are triterpenoids as pentacyclic triterpenes (PT) (Babaee et al., 2013; Martin et al., 2016). Marigold flowers contain a variety of chemical components with positive benefits. The biggest groups of compounds represent flavonoids, polyphenols, saponosides, organic acids and sacharides. C. officinalis also contains carotenoids as triterpenic alcohols in their free and esterified forms. Carotenoid pigments and polyunsaturated acids have inflammatory activity in vivo and inhibitory activity in vitro. Another important group of compounds is polycarbohydrates, which are soluble in water and play a role in tissue soldering and controlling permeability of cells. Other identified substances were proteins and amino acids, saturated hydrocarbons, vitamin $\mathrm{C}$, mineral substances and etheric oils (Butnariu \& Coradini, 2012; Verma et al., 2018). Evaluation of the antioxidant activity of $C$. officinalis revealed its positive effects against different free radicals. The plant extract works as a scavenger of superoxide radicals generated by photoreduction of riboflavin and hydroxyl radicals and also inhibit lipid peroxidation (LPO) (Al-Snafi, 2015).

The aim of this study was to identify major chemical components of the marigold flower extract followed by a comprehensive evaluation of its in vitro effects on selected quality parameters and oxidative profile of bovine spermatozoa.

\section{MATERIAL AND METHODS}

Flowers of marigold (Calendula officinalis) were obtained from the Botanical Garden at the Slovak University of Agriculture in Nitra. The flowers were first dried and then the plant tissues were crushed, weighed and soaked in 96\% ethanol (Centralchem, Bratislava, Slovak Republic). The plant tissue samples were kept in ethanol during two weeks at room temperature in the dark as the sunlight could cause degradation of the bioactive elements. The pextracts were processed through evaporation under reduced pressure at $40{ }^{\circ} \mathrm{C}$ to remove any remains of ethanol (Stuart RE300DB rotary evaporator, Bibby Scientific Limited, UK, and vacuum pump KNF N838.1.2KT.45.18, KNF, Germany). Rough plant extracts were dissolved in DMSO (dimethyl sulfoxide, Sigma-Aldrich, St. Louis, USA) to equal $100.4 \mathrm{mg} / \mathrm{mL}$ as a stock solution.

For the chemical analysis, standard solutions, methanol (HPLC grade), acetonitrile (gradient HPLC grade) and phosphoric acid (ACS grade) were obtained from Sigma-Aldrich. Double deionized water $\left(\mathrm{ddH}_{2} \mathrm{O}\right)$ was obtained using the Simplicity 185 purification system (Millipore SAS, Molsheim, France). Each of the standards was prepared by dissolving $0.5 \mathrm{mg}$ of standard solution in $10 \mathrm{~mL}$ of methanol. After homogenization, every lyophilized sample ( 2 g) was extracted with $20 \mathrm{~mL}$ of $80 \%$ methanol in a horizontal shaker (Unimax 2010; Heidolph Instrument GmbH, Germany) for 8 hours at laboratory temperature. The filtration was done using Munktell No 390 filtration paper (Munktell \& Filtrac, Germany) and the samples were stored in closed $20 \mathrm{~mL}$ vial tubes. Before injection, the extracts and standard solutions were filtered by a Q-Max syringe filter $(0.22 \mathrm{~mm}, 25 \mathrm{~mm}$; Frisenette ApS, Knebel, Denmark) (Bajčan et al., 2016). The chemical compounds of marigold extract were determined using the Agilent 1260 Infinity high performance liquid chromatograph (Agilent Technologies, Waldbronn, Germany) with quaternary solvent manager coupled with degasser (G1311B), sample manager (G1329B), column manager (G1316A) and DAD detector (G1315C). Every HPLC analysis was done on a Purosphere reverse phase C18 column (4 mm x $250 \mathrm{~mm}$ x 5 $\mathrm{mm}$ ) (Merck, KGaA, Darmstadt, Germany). The mobile phase contained acetonitrile (gradient) (A) and $0.1 \%$ phosphoric acid in $\mathrm{ddH}_{2} \mathrm{O}(\mathrm{B})$. The gradient elution proceeded in the following phases: $0-1$ min isocratic elution (20\% A and 80\% B), 1-5 min linear gradient elution (25\% A and 75\% B), 5-15 min (30\% A and 70\% B) and 20-25 
min $(40 \% \mathrm{~A}$ and $60 \% \mathrm{~B})$. The early flow volume was $1 \mathrm{~mL} / \mathrm{min}$ and the injection volume of samples was $10 \mathrm{~mL}$. The temperature of column oven was $30{ }^{\circ} \mathrm{C}$ and the samples were regulated at $4{ }^{\circ} \mathrm{C}$ in the sample manager. The results were collected and evaluated using the Agilent OpenLab ChemStation software for LC 3D Systems (Luksic et al., 2016).

For the in vitro treatment, samples of bovine semen were obtained from Slovenské biologické služby, a.s. in Nitra, Slovakia, and were collected on a single day (in the morning) from sexually mature Holstein bulls by using an artificial vagina. The sample collection was repeated three times. The analysis included the total of 30 samples. After collection, every sample was promptly diluted in physiological saline solution (PS) (sodium chloride $0,9 \%$ w/v, Bieffe Medical, Italia), with the addition of 5\% glucose (Centralchem), 4\% bovine serum albumin (BSA; SigmaAldrich) and supplemented with 0 (control group), 75, 150 and $300 \mu \mathrm{g} / \mathrm{mL}$ of marigold (C. officinalis) extract. The samples were incubated at $37^{\circ} \mathrm{C}$. Sperm motility, mitochondrial activity and ROS production were observed in each group in time periods of 0,2 and 24 hours. At the same time, each sample was centrifuged at $800 \mathrm{x} g$ for $10 \mathrm{~min}$. at $25^{\circ} \mathrm{C}$, the medium was removed and the pellet of cells was sonicated at $28 \mathrm{kHz}$ for 30 seconds on ice using RIPA buffer (Sigma-Aldrich) with protease inhibitor solution for mammalian cell and tissue extracts (Sigma-Aldrich). After this, the samples were centrifuged at $11,828 \times \mathrm{g}$ for $15 \mathrm{~min}$. at $4{ }^{\circ} \mathrm{C}$ to purify the lysates from redundant bits and pieces of cells (Tvrdá et al., 2016). The purified samples with supernatants containing the intracellular content were at $-20{ }^{\circ} \mathrm{C}$ for further analysis.

Sperm motility rate (\%; MOT) was assessed by the computer-aided sperm analysis (CASA, Version 14.0 TOX IVOS II., Hamilton-Thorne Bosciences, Beverly, MA, USA). Every sample (10 $\mu \mathrm{L})$ was placed into Makler counting chamber (depth $10 \mu \mathrm{m}, 37^{\circ} \mathrm{C}$; Sefi Medical Instruments, Haifa, Israel) and immediately processed. For better visualization and avoidance of false positive results, the samples were stained with the IDENT stain. This type of stain is a specific DNA dye based on Hoechst bisbenzimide (Hamilton-Thorne Biosciences) and analyzed under fluorescent light microscope. From every sample ten microscopic fields were observed including at least 300 sperm cells.

Evaluation of the mitochondrial activity was performed using the colometric metabolic activity (MTT) test. This test is based on the transformation of a yellow tetrazolium salt (3-(4,5-dimetylthiazol-2-yl)-2,5-diphenyltetrazolium bromide; MTT) to blue formazan particles by the presence of mitochondrial succinate dehydrogenase of intact mitochondria of living cells. For dilution of tetrazolium salt (Sigma-Aldrich), PBS (Dulbecco's Phosphate Buffer Saline without calcium chloride and magnesium chloride; Sigma-Aldrich) was used at $5 \mathrm{mg} / \mathrm{mL}$. Ten $\mu \mathrm{L}$ of the dissolved tetrazolium solution were added to each sperm sample. The samples were incubated for 2 hours (shaker, 37 ${ }^{\circ} \mathrm{C}, 95 \%$ air atmosphere, $5 \% \mathrm{CO}_{2}$ ). After the incubation, the formazan crystals were dissolved in $80 \mu \mathrm{L}$ of acidified $(0.08 \mathrm{~mol} / \mathrm{L} \mathrm{HCl}$; Centralchem) isopropanol (Centralchem). Optical density was measured using the Multiskan FC microplate photometer (Thermo Fisker Scientific Inc., Waltham, MA, USA) at $570 \mathrm{~nm}$ against $620 \mathrm{~nm}$ as reference. Data are expressed as percentage of the control set to 100\% (Knazická et al., 2012).

Production of ROS in each sample was observed by the chemiluminescence assay using luminol (5-amino-2, 3dihydro-1, 4-phthalazinedione; Sigma-Aldrich) as a probe (Homa et al., 2015). Test samples contained luminol (10 $\mu \mathrm{L}, 5 \mathrm{mmol} / \mathrm{L}$ ) and $400 \mu \mathrm{L}$ of experimental or control sample. In the negative controls, sperm suspension was replaced by $400 \mu \mathrm{L}$ of culture medium. Positive controls included $400 \mu \mathrm{L}$ of each medium, $10 \mu \mathrm{L}$ of luminol and 50 $\mu \mathrm{L}$ of hydrogen peroxide $\left(\mathrm{H}_{2} \mathrm{O}_{2} ; 30 \% ; 8.8 \mathrm{M}\right.$; Sigma-Aldrich). The values of chemiluminescence were evaluated on 48-weel plates in $151 \mathrm{~min}$-cycles using the Glomax Multi ${ }^{+}$Combined Spectro-Fluoro Luminometer (Promega Corporation, Madison, WI, USA) (Ďuračka et al., 2016). The results are expressed as relative light units (RLU)/s/10 ${ }^{6}$ sperm.

Quantification of carbonyl groups was performed by the traditional 2,4-dinitrophenylhydrazine (DNPH) method. One $\mathrm{mL}$ of prepared sample was added to $1 \mathrm{~mL}$ of DNPH $(10 \mathrm{mM}$ in $2 \mathrm{NHCl}$; Sigma-Aldrich). The sample was mixed and incubated for 1 hour at room temperature in the dark. After incubation, $1 \mathrm{~mL}$ of trichloroacetic acid $(20 \%$ w/v; Sigma-Aldrich) was added to the sample and the mixture was incubated for $10 \mathrm{~min}$ at $4{ }^{\circ} \mathrm{C}$. The samples were centrifuged at $11,828 \mathrm{x}$ g for $15 \mathrm{~min}$. Afterwards the supernatant was discarded without pellet destruction and the pellet was immediately washed three times by $1 \mathrm{~mL}$ of ethanol/ethyl acetate $(1 / 1$; v/v) to remove the redundant DNPH. Before absorbance measurement at $360 \mathrm{~nm}$, the pellet sample was resuspended in $1 \mathrm{~mL}$ of $6 \mathrm{M}$ guanidine$\mathrm{HCl}$ (Sigma-Aldrich). To quantify the concentration of protein carbonyl groups, molar absorption coefficient of 22,000 1/M.cm was used. The values of protein carbonyls are expressed as nmol/mg protein (Duračka et al., 2016; Weber et al., 2015).

The level of lipid peroxidation (LPO) was assessed with the help of TBARS (thiobarbituric acid reactive substances) assay, modified for a 96-well plate and ELISA reader. The assay quantifies the malondialdehyde (MDA) production, 
which is the main product of LPO. To each sample 5\% of sodium dodecyl sulfate (Sigma-Aldrich) was added, and the samples were subjected to $0.53 \%$ thiobarbituric acid (TBA; Sigma-Aldrich) dissolved in $20 \%$ acetic adjusted with $\mathrm{NaOH}$ (Centralchem) to $\mathrm{pH} 3.5$, and immediately boiled at $90-100{ }^{\circ} \mathrm{C}$ for $1 \mathrm{~h}$. After boiling, the samples were placed on ice for $10 \mathrm{~min}$ and centrifuged for $10 \mathrm{~min}$ at $1,750 \mathrm{x}$ g. For the measurement of the end-product, we used the supernatant as a product of a chemical reaction between MDA and TBA under high temperature and acidic conditions. The measurement was done with the help of the Multiskan FC microplate photometer (Thermo Fisher Scientific Inc.) set to 530-540 nm (Tvrdá et al., 2016). MDA concentration is expressed as $\mu \mathrm{mol} / \mathrm{g}$ protein.

Statistical analysis was carried out using the GraphPad Prism program (version 6.02 for Windows; GraphPad Software, La Jolla, CA, USA, http://www.graphpad.com). First, descriptive statistical characteristics (mean, standard error) were evaluated. One-way ANOVA was then used for specific statistical evaluations. Dunnett's test was applied as a follow-up test to ANOVA, based on a comparison of every mean to a control mean, and computing a confidence interval for the difference between the two means. The level of significance was set at **** $-\mathrm{P}<$ $0.0001 \mathrm{P} ; * * *-\mathrm{P}<0.001, * *$ - $\mathrm{P}<0.01, *-\mathrm{P}<0.05$.

\section{RESULTS AND DISCUSSION}

Analysis of major chemical components was performed by HPLC. The concentrations of the identified substances are shown in Table 1 and the quantitative determination was performed by the external standard method. Marigold flower extract contained high amounts of phenolic acids and polyphenols. The main detected phenolic acids were rosmarinic $(207.52 \mathrm{mg} / \mathrm{kg}$ ) and chlorogenic $(196.64 \mathrm{mg} / \mathrm{kg})$ acids and polyphenols such as rutin $(34.36 \mathrm{mg} / \mathrm{kg})$. kaempferol $(22.77 \mathrm{mg} / \mathrm{kg})$ and apigenin $(22.01 \mathrm{mg} / \mathrm{kg})$. All others components are also shown in Table 1.

Table 1. Chemical compounds of marigold (Calendula officinalis) flower extract identified by HPLC

\begin{tabular}{ll}
\hline \multicolumn{1}{c}{ COMPOUND } & mg/kg fresh matter \\
\hline \multicolumn{1}{c}{ PHENOLIC ACIDS } \\
\hline Cinnamic acid & $21.99 \pm 2.88$ \\
Ferulic acid & $18.01 \pm 2.01$ \\
Gallic acid & $6.99 \pm 0.78$ \\
Chlorogenic acid & $196.64 \pm 12.21$ \\
Neo-chlorogenic acid & $36.55 \pm 2.55$ \\
Rosmarinic acid & $207.52 \pm 17.98$ \\
Sinapinic acid & $55.30 \pm 4.01$ \\
Trans p-coumaric acid & $7.36 \pm 0.99$ \\
Trans-caffeic acid & $57.97 \pm 3.63$ \\
Trans-ferulic acid & $5.94 \pm 0.67$ \\
Trans-sinapinic acid & $56.32 \pm 4.44$ \\
\hline \multicolumn{2}{c}{ POLYPHENOLS } \\
\hline Catechin & $12.22 \pm 0.98$ \\
Apigenin & $22.01 \pm 2.09$ \\
Cynarosid & $12.99 \pm 1.11$ \\
Daidzein & $14.71 \pm 1.72$ \\
Kaempferol & $22.77 \pm 2.01$ \\
Myricetin & $11.16 \pm 1.02$ \\
Quercetin & $17.42 \pm 1.55$ \\
Resveratrol & $13.80 \pm 1.24$ \\
Rutin & $34.36 \pm 2.87$ \\
Vitexin & $6.27 \pm 0.96$ \\
\hline n=3. Mean $\pm S E M$ & \\
\hline
\end{tabular}

The first observed quality parameter in the in vitro exposure experiment was sperm motility changes in different cultivation times. After 2 hours of cultivation, we could see significantly higher motility $(\mathrm{P}<0.01)$ in the groups exposed to $75 \mu \mathrm{g} / \mathrm{mL}$ and $150 \mu \mathrm{g} / \mathrm{mL}$ marigold flower extract in comparison with the control group. The same results were observed at 24 hours of cultivation. After 24 hours, $300 \mu \mathrm{g} / \mathrm{mL}$ of extract had also significantly positive effect $(\mathrm{P}<0.05)$ on the sperm motility when compared to the control group. The samples containing $75 \mu \mathrm{g} / \mathrm{mL}$ and 150 $\mu \mathrm{g} / \mathrm{mL}$ of marigold extract exhibited the highest motility.

These results contradict Sharma et al. (2013), who studied the antifertility effects of herbal plants in male rats including marigold (C. officinalis). The biggest difference was that their study was done under in vivo conditions, working with only one concentration of extract. They applied aqueous marigold extract (100 mg/kg.b.wt) in water 
for 60 days. After 60 days, the results showed a significant reduction in weight of testes, epididymis, seminal vesicles and ventral prostate of rat males. Also the sperm motility, density and testosterone levels decreased significantly. Accordingly, we may hypothesize that marigold extract exhibits different effects when comparing in vivo and in vitro conditions. While in in vitro conditions the extract had positive and protective effects, in in vivo conditions it had negative effects on the sperm quality and hormone production. Another difference is that Sharma et al. (2013) used male rats as a model while in our study we worked with bovine spermatozoa. Most likely, every type of spermatozoa responds differently to the marigold extract. Furthermore, the positive effects could be suppressed because they used an aqueous extract, and gastric acids in the stomach could cause inactivation of marigold chemical compounds. Kushwaha et al. (2007) also observed this phenomenon in male albino rats. They applied marigold extract orally (200 mg/kg.b.wt) for 60 days like Sharma et al. (2013) and observed the same negative effects on male fertility. Suárez et al. (2012) compared the effects of different herbal plant extract including marigold. They found that $50 \%, 66.7 \%$ and $70 \%$ marigold flower extract had negative effects on the motility and viability of human spermatozoa after 3 and 5 min incubation. After 3 minutes, there was more than $30 \%$ decrease in the motility in all concentrations and after 5 minutes the decrease was more than $40 \%$. In our opinion, the main problem was that they used only water for preparation of the extract and they used very high doses of marigold.

In our study, we used 96\% ethanol for the extract preparation. However, the chemical components of marigold include a lot of substances which are known for their antioxidant effects, including resveratrol, rutin, kaempferol and apigenin. Cui et al. (2016) evaluated the positive antioxidant effects of resveratrol in human spermatozoa. The semen samples from obese infertile males were treated and incubated with $30 \mu \mathrm{mol} / \mathrm{L}$ of resveratrol for $30 \mathrm{~min}$. After incubation, they recorded improvement of sperm motility and other quality parameters. Also, Jamalan et al. (2016) used selected flavonoids to study their possible protection of human spermatozoa. They observed the effects of rutin, kaempferol and quercetin on the recovery of sperm motility and prevention against membrane oxidative damage. Incubation with different concentrations $(25-500 \mu \mathrm{mol} / \mathrm{L})$ of each flavonoid significantly $(\mathrm{P}<0.05 ; \mathrm{P}<0.01)$ improved the sperm motility and viability against the control group. All these flavonoids with antioxidant effects are also present in marigold extract. As such, we may justify the positive effects of these substances on bovine spermatozoa in our experiment. 

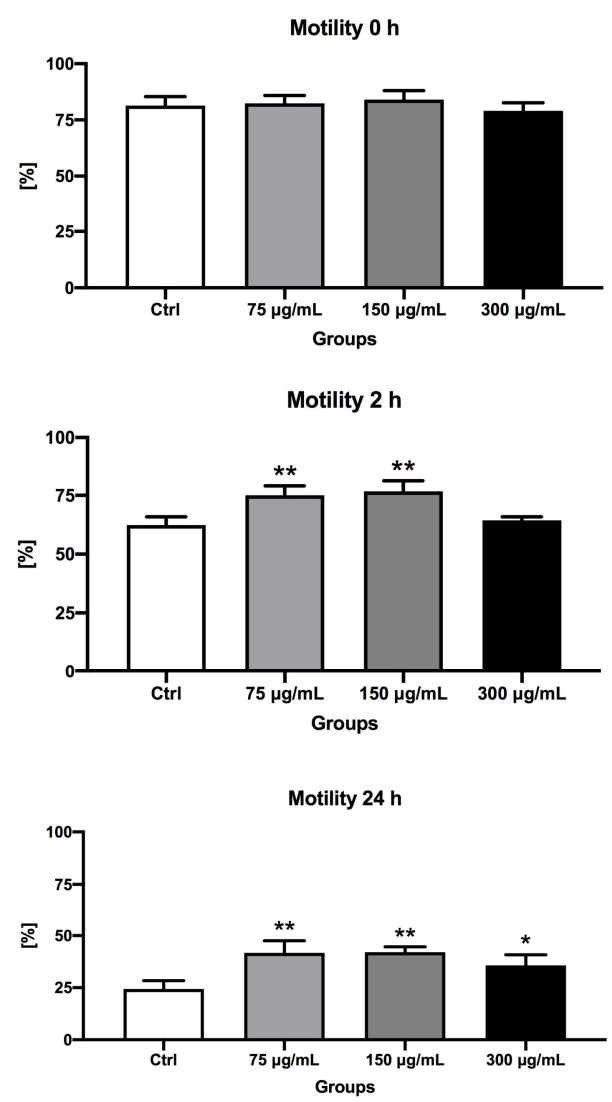

Figure 1. The effect of various concentrations of marigold extract on the motility of bovine spermatozoa at $0 \mathrm{~h}, 2 \mathrm{~h}$ and $24 \mathrm{~h}$. $* * \mathrm{P}<0.01 ; * \mathrm{P}<0.05$.

Mitochondria are one of the most important organelles in the sperm cell as they provide energy needed for proper functioning of metabolism and cell control. Mitochondrial activity is very closely connected to motility because mitochondria also provide energy for sperm movement.

The results of our MTT test are shown in Figure 2. In time 0 there were no statistically significant changes in the experimental groups when compared with the control group. After a 2-hour incubation, the mitochondrial activity significantly increased in the samples with 75 and $150 \mu \mathrm{g} / \mathrm{mL}$ of extract $(\mathrm{P}<0.05$ in case of $75 \mu \mathrm{g} / \mathrm{mL} ; \mathrm{P}<0.01$ with respect to $150 \mu \mathrm{g} / \mathrm{mL}$ ) when compared to the control group. The most significant changes were found after 24 hours of incubation. We observed a phenomenon of continual increase in the samples with $75 \mu \mathrm{g} / \mathrm{mL}(\mathrm{P}<0.0001)$ and 150 $\mu \mathrm{g} / \mathrm{mL}(\mathrm{P}<0.0001)$ against the control group. Similarly to the evaluation of the motility, $75 \mu \mathrm{g} / \mathrm{mL}$ and $150 \mu \mathrm{g} / \mathrm{mL}$ of extract had the most positive and protective effect against the mitochondrial damage. Positive effects of biomolecules found in marigold could be applied also on the protection of mitochondria. Mojica-Villegas et al. (2014) induced oxidative stress by iron/ascorbate in mouse spermatozoa. They used resveratrol for prevention against cell damage caused by oxidative stress. The sperm cells treated with resveratrol demonstrated significant $(\mathrm{P}<0.05)$ decrease of mitochondrial dysfunction and cells were less damaged compared to the control group without resveratrol. 

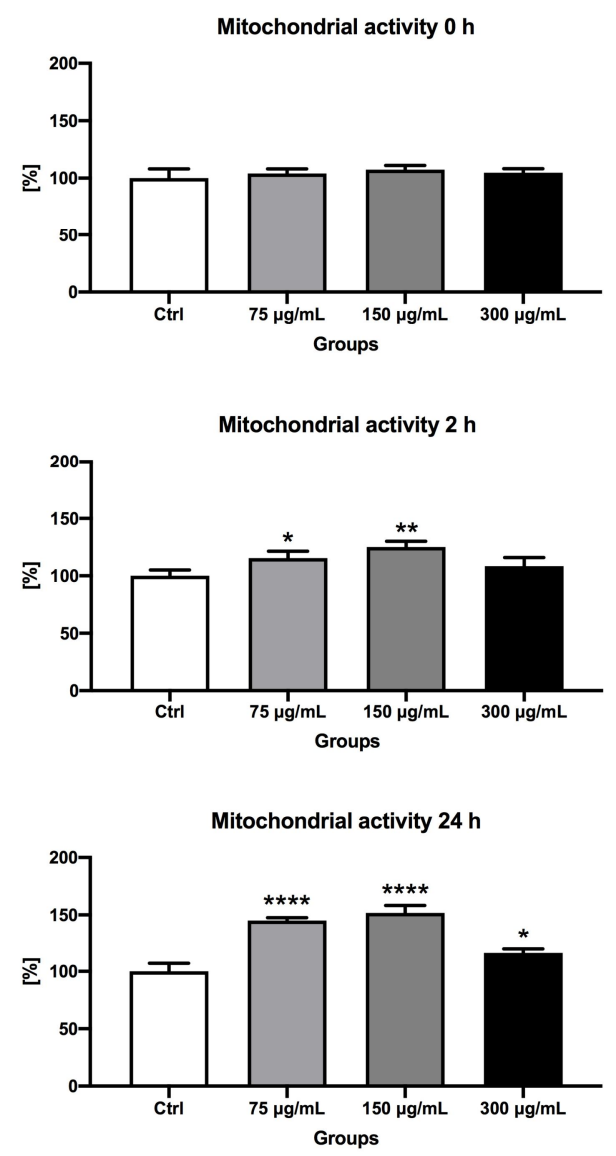

Figure 2. The effect of various concentrations of marigold extract on the mitochondrial activity of bovine spermatozoa at $0 \mathrm{~h}, 2 \mathrm{~h}$ and $24 \mathrm{~h} . * * * * \mathrm{P}<0.0001 ; * * \mathrm{P}<0.01 ; * \mathrm{P}<0.05$

Under physiological conditions, ROS are necessary for the sperm cell metabolism. The problem arises when production of ROS is higher than normal. Higher levels of ROS could lead to OS, which causes decrease of the antioxidant activity and sperm quality. Our results indicate that after 2 hours of incubation, the extract began to exhibit antioxidant effects and decreased production of ROS in the presence of $75 \mu \mathrm{g} / \mathrm{mL}$ and $150 \mu \mathrm{g} / \mathrm{mL}$. Significant differences $(\mathrm{P}<0.05)$ were observed after comparison with the control group without the extract. As was earlier the case, after 24 hours of incubation the positive effect of the extract was even stronger. We recorded significant decrease in ROS production following $75 \mu \mathrm{g} / \mathrm{mL}(\mathrm{P}<0.001)$ and $150 \mu \mathrm{g} / \mathrm{mL}(\mathrm{P}<0.0001)$ of extract in comparison with the control group. On the other hand, the concentration $300 \mu \mathrm{g} / \mathrm{mL}$ of marigold extract showed no antioxidant effects either after 2 hours or after 24 hours of incubation. Preethi et al. (2008) described the antioxidant potential of an extract prepared from Calendula officinalis flowers under in vitro and in vivo conditions. Marigold extract in the in vitro conditions worked as a superoxide radical scavenger. These radicals are generated by the photoreduction of riboflavin and hydroxyl radicals generated by the Fenton reaction. The extract concentrations needed for $50 \%$ inhibition of free radicals production were 500 and $480 \mu \mathrm{g} / \mathrm{mL}$. Antioxidant effects were compared with ginger extract, which was used as a standard antioxidant extract. Marigold also worked as a nitric oxide scavenger in in vitro cell cultures. For the analysis in in vivo conditions, the extract was orally administered to mice for 1 month at a dose of 100 and $250 \mathrm{mg} / \mathrm{kg}$ b.wt. The results showed that oral administration of $C$. officinalis significantly increased the catalase activity, glutatione levels in blood and liver, decreased levels of glutatione peroxidase and inhibited the superoxide production in macrophages. These positive benefits indicated that the extract from C. officinalis had a significant antioxidant activity in vitro and in vivo. Braga et al. (2009) evaluated the antioxidant activity of marigold extract in human neutrophils (polymorphonuclear leukocytes - PMNs) with its positive benefits and antioxidant activity against ROS and reactive nitrogen species (RNS). For the conformation of C. officinalis extract activity, electron paramagnetic resonance (EPR) spectroscopy was used. The extract exhibited anti-ROS and anti-RNS activity, with significant effects already at very low concentration $(0.20 \mu \mathrm{g} / \mathrm{mL}$ without L- 
arginine and $0.10 \mu \mathrm{g} / \mathrm{mL}$ with L-arginine). These findings support the theory about the antioxidant potential and benefits of marigold extract to restore the redox balance in human cells with plant-derived molecules and antagonizing the level of OS.
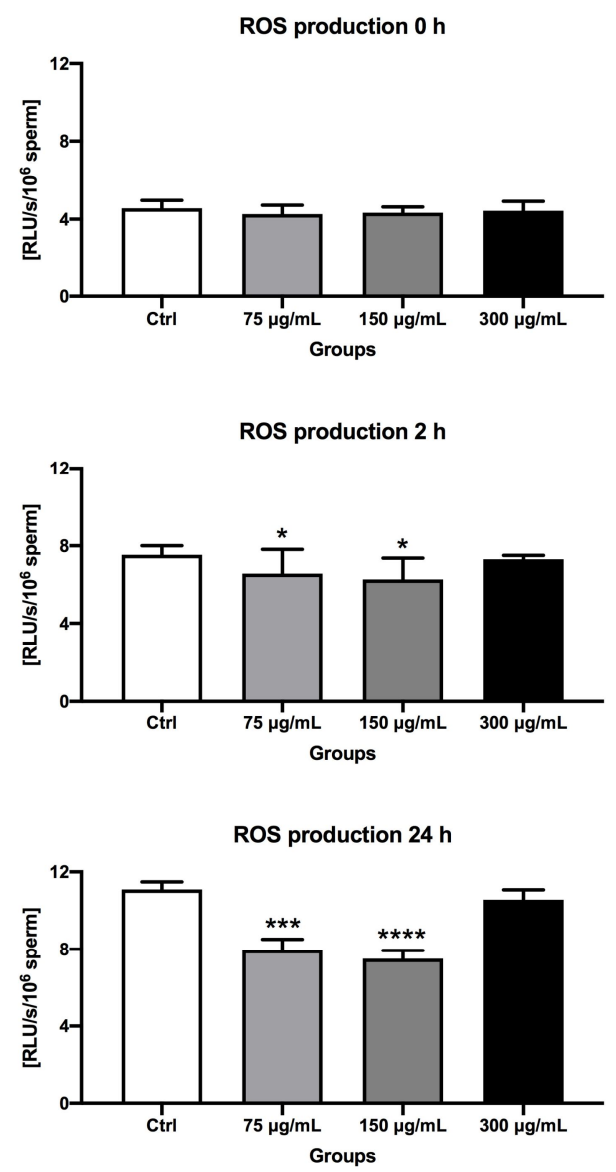

Figure 3. The effect of various concentrations of marigold extract on the production of ROS in bovine spermatozoa at $0 \mathrm{~h}, 2 \mathrm{~h}$ and 24h. $* * * * \mathrm{P}<0.0001 ; * \mathrm{P}<0.05$.

The presence of carbonyl groups in proteins is used as a marker in ROS-mediated protein oxidation. Higher levels of carbonyl groups have toxic effects on sperm cells and may cause irreversible functional damage. As we can see, the protective effects of marigold were visible after 24 hours of incubation. A significantly decreased protein oxidation $(\mathrm{P}<0.01)$ was observed in case of the experimental groups supplemented with $75 \mu \mathrm{g} / \mathrm{mL}$ as well as $150 \mu \mathrm{g} / \mathrm{mL}$ of the extract when compared with the control group. The highest concentration $300 \mu \mathrm{g} / \mathrm{mL}$ had no effects on the level of protein oxidation. Marigold is often combined with other plants like rosemary and grape citrus for improvement of oxidative stability and defense against protein oxidation. These substances are often added in animal feed or diet. For example, a significant decrease of oxidation of biomolecules was observed after addition ( $126 \mathrm{~g} / \mathrm{animal} / \mathrm{day})$ of marigold mixture into cow feed (Falowo et al., 2014). 

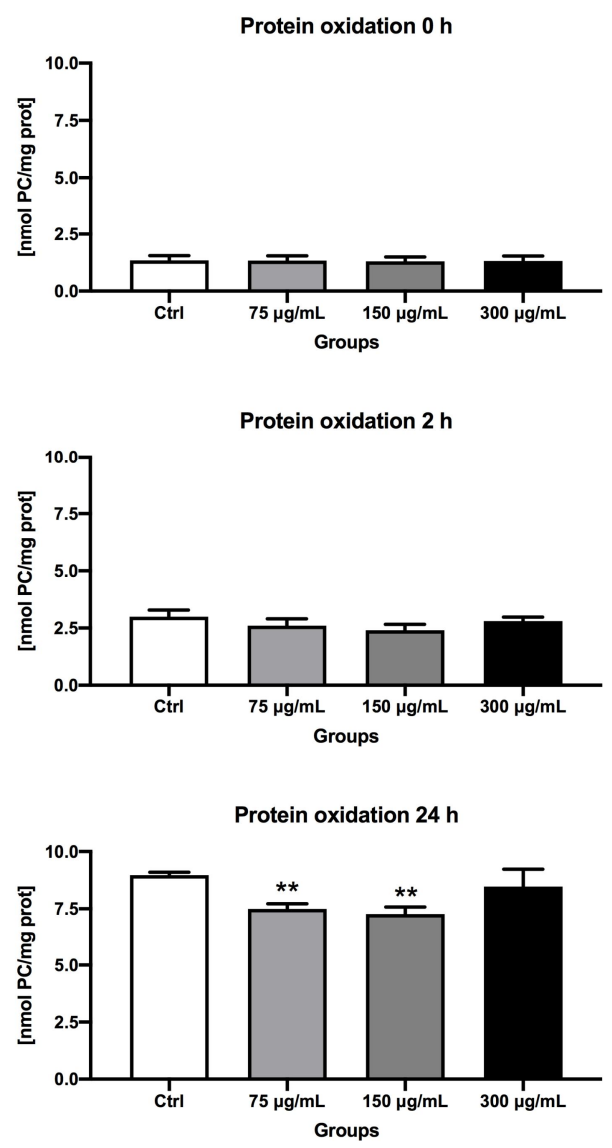

Figure 4. The effect of various concentrations of marigold extract on protein oxidation in bovine spermatozoa at $0 \mathrm{~h}, 2 \mathrm{~h}$ and $24 \mathrm{~h}$. $* * \mathrm{P}<0.01$.

Lipid peroxidation is associated with production of malondialdehyde (MDA). MDA is a toxic substance and causes cell membrane lipid destruction. As Figure 5 shows, the protective effects of marigold extract started after 2 hours of cultivation with decrease of LPO and MDA production. After 24 hours of cultivation, the protective properties of marigold were even stronger and there was a statistically significant decrease of MDA following supplementation of $75 \mu \mathrm{g} / \mathrm{mL}(\mathrm{P}<0.001)$ and $150 \mu \mathrm{g} / \mathrm{mL}(\mathrm{P}<0.0001)$ of the extract in comparison with the control group. The highest concentration $300 \mu \mathrm{g} / \mathrm{mL}$ of the extract exhibited no effects on the level of LPO. Preethi \& Kuttan (2009) evaluated the protective effects of $C$. officinalis flower extract against hepatotoxicity and cisplatin induced nephrotoxicity. Animals treated with $100 \mathrm{mg} / \mathrm{kg}$.b.wt and $250 \mathrm{mg} / \mathrm{kg}$.b.wt extract had significantly lower $(\mathrm{P}<0.01 ; \mathrm{P}<0.001)$ levels of LPO than untreated control animals. Cordova et al. (2002) also observed the protective properties of marigold extract against LPO in rat liver microsomes. Their results showed that butanolic fraction presented in C. officinalis worked as a free radical scavenger and had a therapeutic efficacy in the management of oxidative damage. The calendula extract could be used also for protection against $\mathrm{H}_{2} \mathrm{O}_{2}$ induced chromosome damage (Alnuqaydan et al., 2015). $\mathrm{H}_{2} \mathrm{O}_{2}$ belongs to the ROS category and has negative effects on the cell membrane which leads to development of LPO. Ethanolic extract prepared from marigold $(0.125 ; 0.5 ; 1.0 \%(\mathrm{v} / \mathrm{v}))$ was added to $\mathrm{HaCaT}$ human skin cell culture for protection against ROS induced cytotoxic activity in vitro. Oxidative stress was induced by $300 \mu \mathrm{mol} / \mathrm{L}_{2} \mathrm{O}_{2}$ for $1 \mathrm{~h}$. There were significant differences $(\mathrm{P}<0.05)$ between the cell cultures that were treated and the cell cultures that were not treated with the extract. The treated cells had lower levels of chromosomal and membrane damage caused by OS. Marigold extract protected cells against induced OS in in vitro conditions. 

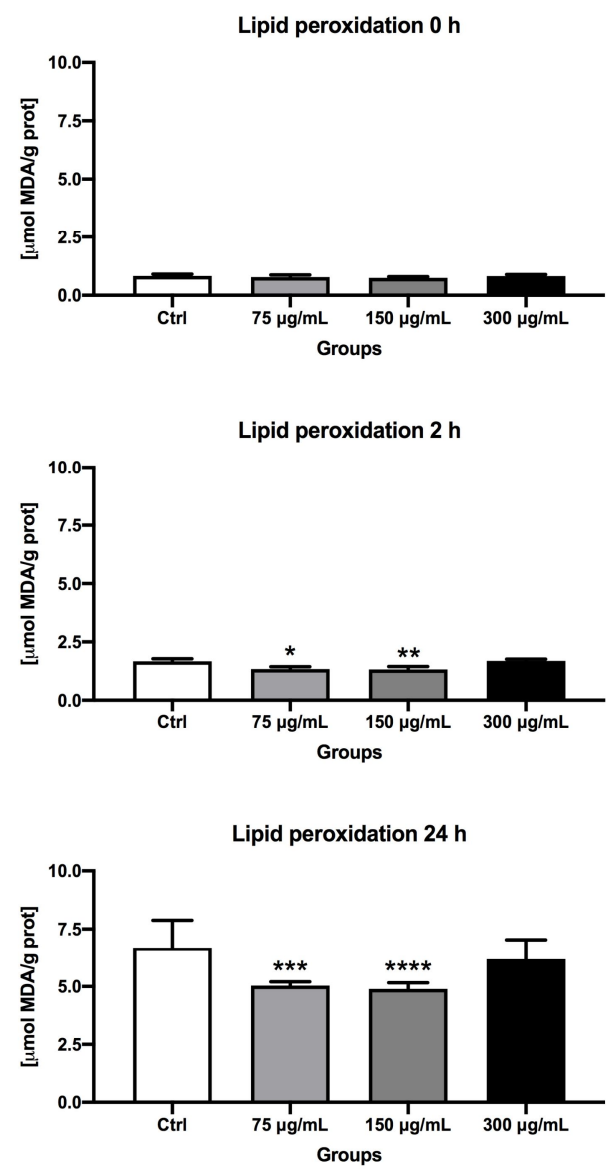

Figure 5. The effect of various concentrations of marigold extract on lipid peroxidation of bovine spermatozoa at $0 \mathrm{~h}, 2 \mathrm{~h}$ and $24 \mathrm{~h}$. $* * * * \mathrm{P}<0.0001 ; * * * \mathrm{P}<0.001 ; * * \mathrm{P}<0.01 ; * \mathrm{P}<0.05$.

\section{CONCLUSION}

This study was focused on a description of the in vitro effects and chemical composition of the medicinal herb Calendula officinalis on the selected quality parameters of bovine spermatozoa. Although the positive and healing properties of marigold are well known, this study tried to evaluate its impact on male reproductive cells. First of all, the extract was subjected to HPLC in order to determine and study the major chemical components of marigold extract. Following HPLC analysis, solutions with different concentrations of marigold extract $(300 ; 150 ; 75 \mu \mathrm{q} / \mathrm{mL})$ were prepared and applied on bovine spermatozoa. The observed and evaluated parameters included sperm motility, mitochondrial activity, production of ROS, protein oxidation and lipid peroxidation. According to the results of this study, it may be concluded that concentrations of 75 and $150 \mu \mathrm{q} / \mathrm{mL}$ extract exhibited significant positive effects on all selected parameters. The observed results in the experimental samples were: increase of motility, mitochondrial activity and decrease of ROS production, protein oxidation and lipid peroxidation. Finally, it may be concluded that the substances present in marigold exhibit positive effects against oxidative stress and decrease oxidative damage to the male gamates following in vitro culture.

Acknowledgements: This study was supported by the European Community Project no. 26220220180: Building Research Centre "AgroBioTech", by the VEGA Project no. 1/0039/16, KEGA Project no. 009SPU-4/2018, and by the Slovak Research and Development Agency Grant no. APVV-15-0544. Experiments of this study were performed with support of the "CeRA" Team of Excellence.

\section{REFERENCES}

Alahmar A. (2019): Role of Oxidative stress in Male Infertility: An Updated Review. Journal of Human Reproductive Sciences, 12(1): 4 . 
Alnuqaydan A., Lenehan C. E., Hudges Ramsay R. (2015): Calendula officinalis Extracts Protect against H2O2 Induced Chromosome Damage on HacaT Human Skin Cells. Journal of Carcinogenesis \& Mutagenesisc, 6(6).

Al-Snafi A. E. (2015): The Chemical Constituents and Pharmacological Effects of Calendula Officinlais - a Review. Indian Journal of Pharmaceutical Science and Research, 5(3): 172-185.

Babaee N., Moslemi D., Khalilpour M.,Vejdani F., Moghadamnia Y., Bijani A., Baradaran M., Kazemi M., Khalipour A., Pouramir M., Moghadamnia A. A. (2013): Atioxidant capacity of calendula officinalis flowers extract and prevention of radiation induced oropharyngal mucositis in patiens with head and neck cancers: a randomized controlled clinical study. Daru: journal of Faculty of Pharmacy, Tehran University of Medical Sciences, 21(1): 18.

Bajčan D., Vollmanová, A., Šimanský V., Bystrická J., Trebichavský, P., Árvay J., Czako P. (2016): Antioxidant activity, phenolic content and colour of the Slovak cabernet sauvignon wines. Potravinárstvo, 10(1): 89-94.

Bisht S., Faiq M., Tolahunase M., Dada R. (2017): Oxidative stress and male infertility. Nature Reviews Urology, 14(8): 470-485.

Braga P., Dal Sasso M., Culici M., Spallino A., Falchi M., Bertelli A., Morelli R., Lo Scalzo R. (2009): Antioxidant activity of Calendula officinalis extract: inhibitory effects on chemiluminescence of human neutrophil bursts and electron paramagnetic resonance spectroscopy. Pharmacology, 83(6): 348-355.

Butnariu M. \& Coradini C. (2012): Evaluation of Biologically Active Compounds from Calendula officinalis Flowers using Spectrophotometry. Chemistry Central Journal, 6: 35.

Cordova C., Siquera I., Netto C., Yunes R., Volpato A., Filho V., Curi-Pedrosa R., Creczynski-Pasa T. (2002): Protective properties of butanolic extract of the Calendula officinalis L. (marigold) against lipid peroxidation of rat liver microsomes and action as free radical scavenger. Redox Report, 7(2): 95-102.

Cui X., Jing X., Wu X., Yan M. (2016): Protective effect of resveratrol on spermatozoa function in male infertility induced by excess weight and obesity. Molecular Medicine Reports, 14(5): 4659-4665.

Duračka M., Tvrdá E., Halenár M., Zbyňovská K., Kolesár E., Lukáč N. (2016): The impact of amygdalin on the oxidative profile of rabbit testicular tissue. MendelNet, 770-775.

Elmussareh M., Mahrous A., Kayes O. (2015): Antioxidant therapy for male subfertility: Myth or evidence-based? Trends in Urology and Mens Health, 35-39.

Falowo A., Fayemi P., Muchenje V. (2014): Natural antioxidants against lipid-protein oxidative deterioration in meat and meat products: A review. Food Research International, 64: 171-181.

Homa S. T., Vessey W., Perez-Miranda A., Riyait T., Agarwal A. (2015): Reactive Oxygen Species (ROS) in human semen: determination of a reference range. Journal of Assisted Reproduction and Genetics, 32: 757-764.

Jamalan M., Ghaffari M., Hoseinzadeh P., Hashemitabar M., Zeinali M. (2016): Human Sperm Quality and Metal Toxicants: Protective Effects of some Flavonoids on Male Reproductive Function. International Journal of Fertility and Sterility, 10(2): 215-222.

Kňažická Z., Tvrdá E., Bardos L., Lukáč N. (2012): Dose- and time- dependent effect of copper ions on the viability of bull spermatozoa in different media. Journal of Environmental Science and Health, Part A, 47(9): 1294-1300.

Kushwaha S., Agarwal M., Mutreja A., Chauhan A. (2007): Impact of 50\% ethanolic extract of Calendula officinalis (flower) on the reproductive function of male albino rats (Rattus norvegicus). Egyptian Journal of Biology, 9(1).

Luksic L., Árvay J., Vollmanová A., Tóth T., Skrabanja V., Trcek J., Germ M., Kreft I. (2016): Hydrothermal treatment of Tartary buckwheat grain hinders the transformation of rutin to quercetin. Journal of Cereal Science, 72: 131-134.

Martin D., Navarro del Hierro J., Villanueva Bermejo D., Fernández-Ruiz R., Fornani T. Reglero G. (2016): Bioaccessibility and Antioxidant Activity of Calendula officinalis Supercritical Extract as Affected by in Vitro Codigestion with Olive oil. Journal of Agricultural and Food Chemistry, 64(46): 8828-8837.

Mojica-Villegaz M., Izquierdo-Vega J., Chamorro-Cevallos G., Sánchez-Gutiérrez M. (2014): Protective effect of resveratrol on biomarkers of oxidative stress induced by iron/ascorbate in mouse spermatozoa. Nutrients, 6(2): 489-503.

Preethi K. C., Kuttan G., Kuttan R. (2008): Antioxidant Potential of an Extract of Calendula officinalis Flowers in Vitro and in Vivo. Pharmaceutical Biology, 44(9): 691-697.

Preethi K. C., Kuttan R. (2009): Hepato and reno protective action of Calendula officinalis L. flower extract. Indian Journal of Experimental Biology, 47(3): 163-168.

Sharma P., Sharma A., Agarwal M., Joshi S. (2013): A review on antifertility efficacy of plants in males. International Journal of Pharma and Bio Sciences, 4(4): 413-428.

Suárez J., Duque D., Gómez Á., Arango V., Cadavid Á, Maya W. (2012): Effects del extracto de Anethum graveolens, Melissa officinalis y Calendula officinalis on the human spermatozoa. Revista Cubana de Plantas Medicinales, 17(4): 420-430.

Tvrdá E., Tušimová E., Kováčik A., Paál D., Libová L., Lukáč N. (2016): Protective effects of quercetin on selected oxidative biomarkers in bovine spermatozoa subjected to ferrous ascorbate. Reproduction of Domestic Animals, 51: 524-537.

Verma P., Raina R., Agarwal S., Kour H. (2018): Phytochemical ingredients and pharmacological potential of Calendula officinalis Linn. Pharmaceutical and Biomedical Research, 4(2): 1-17.

Weber D., Davies M. J., Grune T. (2015): Determination of protein carbonyls in plasma cell extracts, tissue homogenates, isolated proteins: Focus on sample preparation and derivatization conditions. Redox Biology, 5: 367-380.

Received: 10.10.2019.

Accepted: 13.11.2019. 